\title{
Preface to the 50th anniversary issue of the Journal of Materials Science
}

\author{
Mark Aindow ${ }^{1}$
}

Received: 9 October 2015/Accepted: 12 October 2015/Published online: 19 October 2015

(c) Springer Science+Business Media New York 2015

In his book "The Coming of Materials Science" [1], the late Professor Robert Wolfgang Cahn FRS documented the rise of Materials Science as a distinct discipline from its roots in solid-state physics, metallurgy, polymer chemistry, inorganic chemistry, mineralogy, glass, and ceramic technology. The development of the discipline was a process in which he was intimately involved from 1942 when he enrolled at Trinity College, Cambridge to read Metallurgy, to his death from leukemia in 2007. His technical contributions were remarkably diverse, spanning such areas as: defects and deformation mechanisms, crystal growth, recrystallization, intermetallic compounds, and metallic glasses. It was these broad interests that led him to become such a staunch advocate for Materials Science as a discipline. Another of his passions was scientific editing, and he is remembered as much for his editing of several major journals and books as he is for his scientific research work.

In 1964, Robert Cahn was invited by the publishers Chapman and Hall to establish the Journal of Materials Science as the first broad-spectrum Materials Science journal. As Chairman of Editors, he recruited a group of Editors with complementary areas of expertise, gave them independent powers of decision on submitted papers, and encouraged them to be pro-active in soliciting papers from key researchers on novel topics. This helped to ensure that the journal fulfilled its mission of being a broad-spectrum inclusive periodical that brought together work on different classes of materials using a wide variety of different

Mark Aindow

m.aindow@uconn.edu

1 Department of Materials Science and Engineering, Institute of Materials Science, University of Connecticut, Storrs, CT 06269-3136, USA experimental and theoretical approaches. The first issue appeared in April of 1966, and the Journal grew rapidly over the next few years to become a major international forum for research in Materials Science. In Robert Cahn's memoirs [2], he said that the years he devoted to creating the Journal of Materials Science represented his single most important editorial contribution to the field.

Over the last five decades, there have been many changes to the Journal, to the community that it serves, and to the field as a whole. The publishers have undergone several re-organizations and changes of ownership, and are now part of the Springer Nature group. Specialist sister journals have been spun off in the areas of Materials in Electronics and Materials in Medicine, while others such as Interface Science have been incorporated into the main journal. The community has broadened to encompass more biologists, chemists, and physicists due to developments in, for example, tissue engineering, nanostructured catalysts, and functional oxides, respectively. There have also been dramatic changes in the synthesis, processing, characterization, and computational modeling techniques available to materials scientists, and these advances have had a revolutionary effect on research directions in the field. Throughout, the Editors have maintained an open and flexible definition of Materials Science so that the Journal remains true to Robert Cahn's original vision of a broadspectrum publication. This has been helped by stability in the leadership of the Journal with just four Chairmen/ Editors-in-Chief over the first 50 years: Professors Robert Cahn, William Bonfield, Rees Rawlings, and since 2004, C. Barry Carter.

In 2006, the 40th anniversary of the founding of the Journal was marked with a special issue (volume 41, issue 3) comprising reviews, original research articles, and commentaries written by current and former Editors. The 
result was an eclectic collection of high-quality papers that truly captured the tremendous breadth and scope of the Journal. This issue also contained a "Review of Reviews" by Robert Cahn [3], which was the last journal paper of his long and prolific career.

To commemorate the 45th anniversary, we awarded the Sapphire Prize for an outstanding original research paper published in volume 46 of the Journal. Each month, the Editors selected one outstanding paper from that month's issues via a rigorous nomination and voting procedure. The winning paper was then selected from the 12 monthly finalists by a separate international panel of experts drawn from our Editorial and Distinguished Advisory Boards. The winner, "Giant carbon solubility in Au nanoparticles" by Sutter and Sutter [4] was an excellent example of the application of cutting-edge in situ microscopy techniques to novel phenomena in nanoscale materials. The success of the Sapphire Prize in drawing attention to some of the best articles in the Journal led to this process being continued as an annual competition named for our founder: the Journal of Materials Science Robert W. Cahn Best Paper Prize. The papers that have won the "Cahn Prize" over the last 3 years reflect the high quality and broad coverage of the work published in the Journal. The 2012 winner by Pilchak et al. was an experimental investigation of texture effects on fracture in near- $\alpha$ Ti alloys [5]. The 2013 winner was a theoretical and modeling study of dislocation-controlled wear in SiC by Mishra and Szlufarska [6]. The 2014 winner by Meza and Greer concerned the synthesis and deformation characteristics of hollow ceramic nano-lattices [7]. At the time of writing, the finalists for the 2015 Cahn Prize were still being evaluated. Details of the winners and finalists can be found at the main Journal website [8].

The present Editors decided that a suitable way to commemorate both the 50th anniversary of the Journal and the legacy of Robert Cahn would be to have another broadspectrum special issue of the type produced for the 40th anniversary. Contributions were solicited from members of the materials community with close ties to the Journal including: current and former Editors, members of the Editorial and Distinguished Advisory Boards, and authors who publish frequently in the Journal. A total of 45 articles were accepted for inclusion in this special issue, and these range from comprehensive reviews to shorter original research papers and personal perspectives. The comments that follow represent an attempt to place these diverse contributions into some sort of logical sequence.

The articles have been arranged into groups based loosely on the types of materials considered, starting with the conventional classifications of metals, ceramics, and polymers. The first eight papers fall into the broad category of metals and alloys, starting with four reviews. There are three review articles concerning the behavior of ultra-fine- grained and nanostructured materials, an area in which we have had six major special issues over the last decade [volumes(issues): 42(5), 43(23-24), 45(17), 47(22), 48(13), and 49(19)]. The paper by Kumar et al. considers the way in which the classical dichotomy between strength and ductility can be overcome in such materials at low temperatures [9]. Kawasaki and Langdon give an overview of the superplastic properties exhibited by ultra-fine grained materials at elevated temperatures and the flow mechanisms responsible for this behavior [10]. The third review by Murashkin et al. covers the interplay of mechanical strength and electrical conductivity in the $\mathrm{Al}$ and $\mathrm{Cu}$ alloys used in electrical engineering, and the possible role of nanostructure on the mechanisms responsible for these behaviors [11]. The next two papers address issues related to phase transformations in metallic alloys. The review by Yin et al. summarizes our current understanding of phase equilibria in systems containing $\mathrm{Fe}, \mathrm{Co}$, or $\mathrm{Ni}$ that exhibit Heusler-type intermetallic compounds and identifies systems in which further work is required [12]. In the following paper, Suguihiro and Solórzano present an experimental study of discontinuous precipitation phenomena in a $\mathrm{Cu}-\mathrm{Co}$ alloy to reveal the mechanisms responsible for these effects [13]. The last two articles in this group pertain to surface and interface phenomena in metallic alloys. Ahn et al. report a study on the effects of hydrogen reduction on the compressibility of $\mathrm{Cu}$ nanopowders and the subsequent oxidation resistance of the agglomerates [14]. The paper by Campbell considers the consequences of surface oxides being incorporated into metallic materials during consolidation processes; it is proposed that poor bonding across the oxide-oxide interfaces in the resultant bifilms may play a significant role in the failure of a wide range of metallic materials [15].

Next, we have a group of five papers in the area of ceramic science. The first article by Bull et al. revisits the classic problem of chemo-mechanical Rehbinder effects in hardness and wear testing of ceramic materials [16]. Nanoindentation and atomic force microscopy data are used to provide new insights into the nature and significance of these effects. The following two papers concern mechanical effects on phase stability in ceramics. Tiwary et al. present a study of the effects of pressure, temperature, and particle size on the reversible wurtzite to rock-salt phase transformation in $\mathrm{ZnO}$ during ball milling [17]. In the study by Ikoma et al. high-pressure torsion is used to induce allotropic transformations in pure $\mathrm{Ge}$, and the effect of the phase(s) present on the photoluminescence behavior is investigated [18]. We then have two papers about electron microscopy studies of spinel oxides. The article by Winterstein et al. describes in situ transmission electron microscopy (TEM) studies of $\mathrm{MgAl}_{2} \mathrm{O}_{4}$ spinel formation by a reaction between $\mathrm{MgO}$ nano-cubes and single-crystal 
sapphire substrates [19]. Changes in the orientation relationship between the spinel and the substrate with reaction temperature are used to infer a change in the rate-controlling diffusive processes. Gambino et al. present a TEM study of cation site occupancy effects in $\mathrm{Cr}-$, $\mathrm{Ni}-$, and $\mathrm{Fe}-$ substituted manganese cobaltite spinels using X-ray spectrometry Atom Location by Channeling Enhanced MIcroanalysis (ALCHEMI) experiments [20].

The third group of papers relate to polymeric materials. The first paper by Patterson et al. describes the use of synchrotron-based X-ray tomographic imaging techniques to study the dynamic response of polymer foams to mechanical stress [21]. It is shown that this novel approach can provide an accurate representation of the deforming cellular structure even at high strain rates that give hyperelastic responses. Next, we have three papers on polymeric fibers. The paper by Wang et al. concerns the use of a meltbased co-extrusion, multiplication, and delamination approach to produce polypropylene/polyamide micro-fibers [22]. This approach enables the fiber properties, such as surface area and porosity, to be tuned to optimize the fibers for filtration applications. In a similar vein, Chattopadhyay et al. describe the use of electrospinning to produce cellulose acetate fibers for aerosol filtration applications [23]. Here again, it was shown that the properties of the fibers can be controlled to modify filtration performance. Wanasekara et al. use the electrospinning approach to produce polystyrene and poly(vinyl alcohol) nano-fibers containing cellulose nano-crystals [24]. It is shown that there are limitations on the degree of alignment for these nano-crystals, and that this has a significant impact on the mechanical behavior of the fibers. The next four papers continue the theme of processing-structure-property relationships in polymers. Bandeira et al. use wide-angle X-ray diffraction to reveal the effect of draw ratio on crystalline orientation in semi-crystalline polymers [25]. A new model based on the geometry of the crystalline slip mechanism is used to account for these effects. Keller et al. consider the effects of silica nanoparticles on the thermal characteristics of epoxy polymer curing and develop a kinetic/rheological model to explain their observations [26]. Banerjee and Bhowmick describe a study on the visco-elastic properties and melt rheology of novel polyamide 6/fluoroelastomer nanostructured thermoplastic vulcanizates [27]. Lastly, Sharma et al. report a study on the erosive and sliding wear characteristics of polybenzimidazole [28].

The following group of papers is on the general theme of composites. When the journal was founded, one of the goals was to provide a forum for papers on the emerging category of composite materials. Composites have remained an important part of the remit for the journal throughout the last 50 years, although the definition has expanded far beyond what was originally envisaged. This development was described in the late Professor Anthony Kelly's review article in the 40th Anniversary Issue [29]. It has also been charted in several special issues since then [volumes(issues): 41(13), 41(20), 43(13), 43(20), 44(6), and 47(15)], including a 2008 festschrift (volume 43, issue 12) in honor of our former Editor-in-Chief, Rees Rawlings, who made many important contributions in this area. The seven papers in this group reflect well the diverse character of composite materials. The review article by Utech and Boccaccini is a survey of hydrogel-based polymer matrix composites with inorganic fillers as reinforcements for use in biomedical applications such as regenerative medicine, tissue engineering, and cell culture techniques [30]. We then have three papers that deal with different aspects of carbon-reinforced polymer matrix composites. Chou et al. consider how variations in fiber strength and local fiber volume fraction contribute to the scatter in the tensile properties of uni-directional carbon/epoxy composites [31]. Wang et al. report a microbond testing study on the effects of thermal residual stress on interfacial properties in polyphenylene sulfide/carbon fiber composites [32]. Young et al. present a study on internal and interfacial stress transfer in carbon nanotube/epoxy composites [33]. They demonstrate that the effective modulus and stress transfer is far higher for single-wall than for multi-wall nanotubes due to inter-layer slippage in the latter case. The following paper by Williams et al. concerns ceramic/ceramic composites (specifically $\mathrm{SiC}-\mathrm{B}_{4} \mathrm{C}$ ) and the effect of the initial interfacial area on the densification and the microstructural development in these materials [34]. The last two papers in this group are rather different. The article by Van Niejenhuis et al. concerns the corrosion resistance of stainless steel reinforcements in cracked concrete matrices [35]. Haile et al. report the formation of a polyelectrolyte multilayer coating with aluminum hydroxide that imparts superior fire-retardant properties to a polyurethane foam substrate [36].

The articles in the fifth group have the common theme of defects, interfaces, and related phenomena. Such topics have been part of the remit for the Journal since its inception, but the incorporation of Interface Science in 2005 led to a significant increase in submissions in this area. There have also been several special issues and sections on interface science and related topics such as intergranular and interphase boundaries in materials [volumes(issues): 40(12), 43(11), 46(12), and 49(11)] and high-temperature capillarity [40(9-10), 45(8), and 47(24)]. There are three review articles in this section on very different aspects of this theme. The first is a review of grain boundary faceting and roughening phenomena by Straumal et al. [37]. The second review by Saka is a historical overview of the factors that affect the dissociation with of extended dislocations in FCC metals and alloys, with 
particular emphasis on the influence of Suzuki segregation [38]. The third is a discussion by Eustathopoulos and Voytovych of the role that interfacial reactions play in the wettability of solid metal and ceramic surfaces by liquid metals [39]. We then have two papers on the experimental quantification of interfacial segregation. Huang et al. use a combination of atom-probe tomography and aberrationcorrected scanning transmission electron microscopy (STEM) to measure grain boundary segregation in Al-Mn electrodeposits; these data are used to extract the grain boundary segregation energy [40]. Barrett et al. use a combination of secondary ion mass spectrometry and STEM to quantify interfacial contamination in GaAs grown epitaxially on (001)Si, and to relate this to the density of anti-phase boundaries in the deposit [41]. The last two papers in this group relate the structure and configurations of boundaries to the mechanisms by which they move. Muntifering et al. present in situ straining and conventional TEM observations of inter-variant twin boundaries in a non-modulated $\mathrm{Ni}-\mathrm{Mn}-\mathrm{Ga}$ shape memory alloy; these observations are interpreted in terms of the Müllner-King mechanism by which a lamellar twin/matrix composite is transformed into its conjugate [42]. Sternlicht et al. describe an aberration-corrected TEM study of grain boundaries in $\mathrm{SrTiO}_{3}$ and use the structure and morphology of the boundaries to deduce the boundary migration mechanism [43].

Next, we have four papers on the electronic properties of materials. While much of the work in this area goes to our sister journal, Materials in Electronics, there has been a resurgence of interest in publishing such articles in the main journal. Two main areas have driven this trend: functional oxides as exemplified by the papers in two large special issues on ferroelectrics [41(1) and 44(19)], and articles on first-principles computations of electronic structure and properties such as those in a 2012 special issue on this topic (volume 47, issue 21). The first article in this group is an experimental study by Prasertpalichat and Cann on the effects of A-site non-stoichiometry in leadfree $\mathrm{Bi}_{0.5} \mathrm{Na}_{0.5} \mathrm{TiO}_{3} / \mathrm{BaTiO}_{3}$ piezoelectric ceramics [44]. The differences in behavior are termed collectively "hardening" and are explained on the basis of changes in the long-range domain structure and defect chemistry. This is followed by three theoretical/computational studies. Misirlioglu et al. report a thermodynamic modeling study which demonstrates that ferroelectric-paraelectric superlattice heterostructures can exhibit on/off switching properties at much lower bias voltages than in a linear high dielectric constant gate [45]. They propose that such constructs can be employed as gate materials for field effect transistors. Using a similar methodology, Sun et al. address the question "Are ferroelectric multilayers capacitors in series?" and demonstrate that the answer is "No" except in cases where both ferroelectrics are dielectrics, or the individual layers are screened from one another [46]. In the fourth paper, Chen et al. use density functional theory computations to calculate the barriers to charge injection at metal/polyethylene interfaces [47]. It is shown that the barrier is determined by the combined effect of the metal work function and the vacuum shift due to the interfacial dipole, which depends on the details of the structure and bonding at the interface.

Lastly, we have a group of papers in the broad area of nanomaterials. Firstly, we have a comprehensive review by Bao et al. of iron oxide nanoparticles ranging from materials engineering (size and shape control, large-area selfassembly, composite/hybrid structures, and surface engineering) to emerging applications (nanoparticle lithography, magnetic particle imaging, magnetic guided drug delivery, and positive contrast agents for magnetic resonance imaging) [48]. We then have two papers on carbon nanostructures. Chung presents a review on exfoliated graphite with emphasis on the exfoliation process, together with the structure, properties, and potential applications for the resultant materials [49]. Kamali and Fray present a study on the electrochemical interactions between molten salts and graphite to produce a range of different carbon nanostructures including: nanotubes, nanoparticles, graphene, and nanodiamonds [50]. The following two papers are on tin nanostructures. Owen and Norton report the electrochemical synthesis of Sn nano-needles and use the variation of needle morphology with deposition conditions to reveal the mechanism of nano-needle formation [51]. Janish et al. describe in situ TEM studies of the lithiation/ delithiation of $\mathrm{Sn}$ nano-needles and show that the reversibility of the process may depend upon the lithiation conditions and the character of the $\mathrm{Sn} / \mathrm{Li}$ phases produced [52]. The next paper by da Silva et al. concerns $\mathrm{Au} / \mathrm{Pd}$ and $\mathrm{Ag} / \mathrm{Pd}$ nano-flowers as catalysts; it is shown that the catalytic activity depends critically on the sizes, compositions, and morphologies of these nanostructures [53]. Lastly, we have an article from Detsi et al. on metallic nano-foams and nano-porous metal-polymer composite materials as "artificial muscles" [54]. These structures produce mechanical responses to electrical stimuli which are orders of magnitude larger than conventional actuator materials, and they also have tremendous potential as anodes for high-performance water electrolyzers and in next-generation lithium-ion batteries.

In summary, this 50th anniversary collection of papers illustrates some of the historical strengths, recent developments, and future directions in Materials Science. The diverse range of topics certainly fits Robert Cahn's original vision of a broad-spectrum journal. We are confident that Robert would have been pleased with the direction in which we have taken the journal that he founded. 
Acknowledgements I would like to thank all of the contributing authors, the peer-reviewers, and the staff at Springer for their assistance in bringing this project to fruition. Completing the process of submission, evaluation, revision, and production in time for the 50th Anniversary Issue to appear on time required the co-operation of many people, often on unreasonably tight schedules. I am particularly grateful to Saraswathi Sabapathy in the Springer Journals Editorial Office and Robert Maged in the Springer Production Department; without all their efforts behind the scenes, special issues such as this would simply not be possible.

\section{References}

1. Cahn RW (2001) The coming of materials science. Elsevier, Oxford

2. Cahn RW (2005) The art of belonging: a memoir. Book Guild Publishing, Sussex, pp 64-65

3. Cahn RW (2006) A review of reviews. J Mater Sci 41(3):593-596. doi:10.1007/s10853-006-6473-3

4. Sutter EA, Sutter PW (2011) Giant carbon solubility in Au nanoparticles. J Mater Sci 46(22):7090-7097. doi:10.1007/ s10853-011-5663-9

5. Pilchak AL, Porter WJ, John R (2012) Room temperature fracture processes of a near- $\alpha$ titanium alloy following elevated temperature exposure. J Mater Sci 47(22):7235-7253. doi:10.1007/ s10853-012-6673-y

6. Mishra M, Szlufarska I (2013) Dislocation controlled wear in single crystal silicon carbide. J Mater Sci 48(4):1593-1603. doi:10.1007/s10853-012-6916-y

7. Meza LR, Greer JR (2014) Mechanical characterization of hollow ceramic nanolattices. J Mater Sci 49(6):2496-2508. doi:10.1007/ s10853-013-7945-x

8. Journal of Materials Science. http://www.springer.com/materials/ journal/10853

9. Kumar P, Kawasaki M, Langdon TG (2016) Review: overcoming the paradox of strength and ductility in ultrafine-grained materials at low temperatures. J Mater Sci 51(1). doi:10.1007/s10853-015-9143-5

10. Kawasaki M, Langdon TG (2016) Review: achieving superplastic properties in ultrafine-grained materials at high temperatures. J Mater Sci 51(1). doi:10.1007/s10853-015-9176-9

11. Murashkin MYu, Sabirov I, Sauvage X, Valiev RZ (2016) Nanostructured $\mathrm{Al}$ and $\mathrm{Cu}$ alloys with superior strength and electrical conductivity. J Mater Sci 51(1). doi:10.1007/s10853-015-9354-9

12. Yin $M$, Hasier J, Nash $P$ (2016) A review of phase equilibria in Heusler Alloy systems containing Fe, Co or Ni. J Mater Sci 51(1). doi:10.1007/s10853-015-9389-y

13. Suguihiro NM, Solórzano IG (2016) On the initiation, growth and coarsening of discontinuous precipitation in $\mathrm{Cu}-10$ at.\% Co alloy. J Mater Sci 51(1). doi:10.1007/s10853-015-9391-4

14. Ahn D-H, Kim W, Yoon EY, Kim HS (2016) Compressibility of hierarchic architectured agglomerates of hydrogen-reduced copper nanopowders. J Mater Sci 51(1). doi:10.1007/s10853-0159414-1

15. Campbell $\mathbf{J}$ (2016) The consolidation of metals: the origin of bifilms. J Mater Sci 51(1). doi:10.1007/s10853-015-9399-9

16. Bull SJ, Moharrami N, Hainsworth SV, Page TF (2016) The origins of chemomechanical effects in the low-load indentation hardness and tribology of ceramic materials. J Mater Sci 51(1). doi:10.1007/s10853-015-9412-3

17. Tiwary CS, Kole AK, Vishnu D, Brahmanandam J, Mahapatra DR, Kumbhakar P, Chattopadhyay K (2016) Stabilization of the high temperature and high pressure cubic phase of $\mathrm{ZnO}$ by temperature controlled milling. J Mater Sci 51(1): this issue. doi:10.1007/s10853-015-9394-1
18. Ikoma Y, Toyota T, Ejiri Y, Saito K, Guo Q, Horita Z (2016) Allotropic phase transformation and photoluminescence of germanium nanograins processed by high-pressure torsion. J Mater Sci 51(1). doi:10.1007/s10853-015-9328-y

19. Winterstein JP, Sezen M, Recnik A, Carter CB (2016) Electron microscopy observations of the spinel-forming reaction using $\mathrm{MgO}$ nanocubes on $\mathrm{Al}_{2} \mathrm{O}_{3}$ substrates. J Mater Sci 51(1). doi:10. 1007/s10853-015-9366-5

20. Gambino LV, Freeman AB, Magdefrau NJ, Aindow M (2016) ALCHEMI studies of site occupancies in $\mathrm{Cr}-$, Ni- and Fe-substituted manganese cobaltite spinels. J Mater Sci 51(1). doi:10. 1007/s10853-015-9307-3

21. Patterson BM, Cordes NL, Henderson K, Williams JJ, Stannard T, Singh SS, Rodriguez Ovejero A, Xiao X, Robinson M, Chawla N (2016) In situ X-ray synchrotron tomographic imaging during the compression of hyperelastic polymeric materials. J Mater Sci 51(1). doi:10.1007/s10853-015-9355-8

22. Wang J, Ayyar R, Olah A, Baer E (2016) Processing-structureproperty relationships of novel fibrous filters produced by a meltprocess. J Mater Sci 51(1). doi:10.1007/s10853-015-9380-7

23. Chattopadhyay S, Hatton TA, Rutledge GC (2016) aerosol filtration using electrospun cellulose acetate fibers. J Mater Sci 51(1). doi:10.1007/s10853-015-9286-4

24. Wanasekara ND, Santos RPO, Douch C, Frollini E, Eichhorn SJ (2016) Orientation of cellulose nanocrystals in electrospun polymer fibres. J Mater Sci 51(1). doi:10.1007/s10853-015-9409y

25. Bandeira B, Lewis ELV, Barton DC, Ward IM (2016) The degree of crystalline orientation as a function of draw ratio in semicrystalline polymers: a new model based on the geometry of the crystalline chain slip mechanism. J Mater Sci 51(1). doi:10. 1007/s10853-015-9220-9

26. Keller A, Masania K, Taylor AC, Dransfeld C (2016) Fast-curing epoxy polymers with silica nanoparticles: Properties and rheokinetic modelling. J Mater Sci 51(1). doi:10.1007/s10853-0159158-y

27. Banerjee SS, Bhowmick AK (2016) Viscoelastic properties and melt rheology of novel polyamide 6/fluoroelastomer nanostructured thermoplastic vulcanizates. J Mater Sci 51(1). doi:10.1007/ s10853-015-9187-6

28. Sharma S, Padenko E, Bijwe J, Wetzel B, Friedrich K (2016) Erosive and sliding wear of polybenzimidazole at elevated temperatures. J Mater Sci 51(1). doi:10.1007/s10853-015-9381-6

29. Kelly A (2006) Composite materials after seventy years. J Mater Sci 41(3):905-912. doi:10.1007/s10853-006-6569-9

30. Utech S, Boccaccini AR (2016) A review of hydrogel-based composites for biomedical applications: Enhancement of hydrogel properties by addition of rigid inorganic fillers. J Mater Sci 51(1). doi:10.1007/s10853-015-9382-5

31. Chou HY, Thionnet A, Mouritz A, Bunsell AR (2016) Stochastic factors controlling the failure of carbon/epoxy composites. J Mater Sci 51(1). doi:10.1007/s10853-015-9390-5

32. Wang X, Xu D, Liu H-Y, Zhou H, Mai Y-W, Yang J, Li E (2016) Effects of thermal residual stress on interfacial properties of polyphenylene sulfide/carbon fiber (PPS/CF) composite by microbond test. J Mater Sci 51(1). doi:10.1007/s10853-015-92512

33. Young RJ, Deng L, Wafy TZ, Kinloch IA (2016) Interfacial and internal stress transfer in carbon nanotube based nanocomposites. J Mater Sci 51(1). doi:10.1007/s10853-015-9347-8

34. Williams T, Yeomans J, Smith P, Heaton A, Hampson C (2016) Effect of interfacial area on densification and microstructural evolution in silicon carbide-boron carbide particulate composites. J Mater Sci 51(1). doi:10.1007/s10853-015-9384-3

35. Van Niejenhuis CV, Walbridge S, Hansson CM (2016) The performance of austenitic and duplex stainless steels in cracked 
concrete exposed to concentrated chloride brine. J Mater Sci 51(1). doi:10.1007/s10853-015-9387-0

36. Haile M, Fomete S, Lopez ID, Grunlan JC (2016) Aluminum hydroxide multilayer assembly capable of extinguishing flame on polyurethane foam. J Mater Sci 51(1). doi:10.1007/s10853-0159258-8

37. Straumal BB, Kogtenkova OA, Gornakova AS, Sursaeva VG, Baretzky B (2016) Review: grain boundary faceting-roughening phenomena. J Mater Sci 51(1). doi:10.1007/s10853-015-9341-1

38. Saka H (2016) Factors affecting the dissociation width of dissociated dislocations in FCC metals and alloys. J Mater Sci 51(1). doi:10.1007/s10853-015-9335-z

39. Eustathopoulos N, Voytovych R (2016) The role of reactivity in wetting by liquid metals: a review. J Mater Sci 51(1). doi:10. 1007/s10853-015-9331-3

40. Huang T-Y, Marvel CJ, Cantwell PR, Harmer MP, Schuh CA (2016) Grain boundary segregation in Al-Mn electrodeposits prepared from ionic liquid. J Mater Sci 51(1). doi:10.1007/ s10853-015-9316-2

41. Barrett CSC, Lind AG, Bao X, Ye Z, Ban KY, Martin P, Sanchez E, Xin Y, Jones KS (2016) Quantitative correlation of interfacial contamination and antiphase domain boundary density in gaAs on Si(100). J Mater Sci 51(1). doi:10.1007/s10853-015-9334-0

42. Muntifering B, Kovarik L, Browning ND, Pond RC, Knowlton WB, Müllner P (2016) Stress-assisted removal of conjugation boundaries in non-modulated Ni-Mn-Ga by coordinated secondary twinning. J Mater Sci 51(1). doi:10.1007/s10853-015-9236-1

43. Sternlicht H, Rheinheimer W, Hoffmann MJ, Kaplan WD (2016) The mechanism of grain boundary motion in $\mathrm{SrTiO}_{3}$. J Mater Sci 51(1). doi:10.1007/s10853-015-9058-1

44. Prasertpalichat S, Cann DP (2016) Hardening in non-stoichiometric $(1-\mathrm{x}) \mathrm{Bi}_{0.5} \mathrm{Na}_{0.5} \mathrm{TiO}_{3}-\mathrm{xBaTiO}_{3}$ lead free piezoelectric ceramics. J Mater Sci 51(1). doi:10.1007/s10853-015-9235-2

45. Misirlioglu IB, Sen C, Kesim MT, Alpay SP (2016) Low-voltage ferroelectric-paraelectric superlattices as gate materials for field effect transistors. J Mater Sci 51(1). doi:10.1007/s10853-0159301-9

46. Sun F-C, Kesim MT, Espinal Y, Alpay SP (2016) Are ferroelectric multilayers capacitors in series? J Mater Sci 51(1). doi:10.1007/s10853-015-9301-9

47. Chen L, Huan TD, Cardona Quintero Y, Ramprasad R (2016) Charge injection barriers at metal/polyethylene interfaces. J Mater Sci 51(1). doi:10.1007/s10853-015-9369-2

48. Bao Y, Wen T, Samia ACS, Khandhar A, Krishnan KM (2016) Magnetic nanoparticles: material engineering and emerging applications in lithography and biomedicine. J Mater Sci 51(1). doi:10.1007/s10853-015-9324-2

49. Chung DDL (2016) A review of exfoliated graphite. J Mater Sci 51(1). doi:10.1007/s10853-015-9284-6

50. Kamali A, Fray D (2016) Electrochemical interaction between graphite and molten salts to produce nanotubes, nanoparticles, graphene and nanodiamonds. J Mater Sci 51(1). doi:10.1007/ s10853-015-9340-2

51. Owen CD, Norton MG (2016) Growth mechanism of one dimensional tin nanostructures by electrodeposition. J Mater Sci 51(1). doi:10.1007/s10853-015-9323-3

52. Janish MT, Mackay DT, Liu Y, Jungjohann KL, Carter CB, Norton MG (2016) TEM in-situ lithiation of tin nanoneedles for battery applications. J Mater Sci 51(1). doi:10.1007/s10853-0159318-0

53. da Silva AGM, Rodrigues TS, Taguchi LSK, Fajardo HV, Balzer R, Probst LFD, Camargo PHC (2016) Pd-based Nanoflowers catalysts: controlling size, composition and structures for the 4-nitrophenol reduction and and BTX oxidation reactions. J Mater Sci 51(1). doi:10.1007/s10853-015-9315-3

54. Detsi E, Tolbert SH, Punzhin S, De Hosson JThM (2016) Metallic muscles and beyond: nanofoams at work. J Mater Sci 51(1). doi:10.1007/s10853-015-9317-1 